\title{
ANALISIS PENERAPAN CONTRACTOR SAFETY MANAGEMENT SYSTEM (CSMS) DI PT. X, BONTANG, KALIMANTAN TIMUR
}

\author{
THE ANALYSIS OF CONTRACTOR SAFETY MANAGEMENT SYSTEM (CSMS) \\ IMPLEMENTATION ON PT. X, BONTANG, KALIMANTAN TIMUR
}

\author{
Hera Yulinanda Pratiwi \\ PT. Bumi Sehat Lestari Surabaya, Jawa Timur \\ E-mail: herayulinandap@yahoo.com
}

\begin{abstract}
PT. X engaged in agrochemical industry which continuously develops, improves and modify the plant and supporting facilities by appointing contractors/subcontractors as the executor of work. PT. X implements Contractor Safety Management System (CSMS) which is outlined in the SMT-KKK-26 procedure as an effort to control that contractor applied safety and health standards. After the procedure implemented, there are still some cases of work accidents happened to PT. X's contractor workers. This study aims to analyze the implementation of CSMS that has been poured in SMT-KKK-26 PT. X using PDCA cycle (Plan, Do, Check, Action). This research was conducted using cross sectional approach with descriptive data analysis and conducted at PT. X, Bontang, East Kalimantan from February to March 2017. The SMT-KKK-26 procedure regulate the passage of the procurement process in PT. X by implementing the stages of CSMS by several departments. Based on the result of the observation can be concluded that the implementation of CSMS on PT. $X$ still needs some improvement to fit the PDCA cycle rules. There were 154 contractors capable of fulfilling the CSMS document and becoming the partner of PT. X. However, the implementation of plan that covering risk identification, pre qualification, and selection in the SMT-KKK-26 procedure still needs improvement because it was not in accordance with the procurement of services in the field due to organizational structure changes in PT. X. Similarly, the implementation of do, check, and action can run more optimally if there is a standard evaluation form to assess the work performed by the contractor.
\end{abstract}

Keywords: CSMS, PDCA cycle, procedure, contractor

\begin{abstract}
ABSTRAK
PT. X bergerak dalam bidang industri agrokimia yang terus melakukan pengembangan, perbaikan dan modifikasi terhadap pabrik dan sarana pendukungnya dengan menunjuk perusahaan kontraktor/subkontraktor sebagai pelaksana pekerjaan. PT. X menerapkan Contractor Safety Management System (CSMS) yang dituangkan dalam Prosedur SMT-KKK-26 sebagai upaya pengendalian agar pekerjaan yang dilakukan oleh kontraktor menerapkan norma keselamatan dan kesehatan kerja. Setelah prosedur tersebut diterapkan, masih terjadi beberapa kasus kecelakaan kerja pada pekerja kontraktor PT. X. Penelitian ini bertujuan untuk melakukan analisis terhadap pelaksanaan CSMS yang telah dituangkan dalam SMT-KKK-26 PT. X menggunakan siklus PDCA (Plan, Do, Check, Action). Penelitian ini dilaksanakan menggunakan pendekatan cross sectional dengan analisa data deskriptif. Penelitian dilaksanakan di PT. X, Bontang, Kalimantan Timur pada bulan Februari hingga Maret 2017. Prosedur SMT-KKK-26 PT. X mengatur berjalannya proses pengadaan jasa dengan menerapkan tahapan CSMS yang dilaksanakan oleh beberapa departemen. Berdasarkan hasil pengamatan terhadap penerapan Contractor Safety Management System (CSMS) di PT. X dapat disimpulkan bahwa CSMS yang dilaksanakan pada PT. X tersebut masih memerlukan beberapa perbaikan agar sesuai dengan kaidah siklus PDCA, Plan-Do-Check-Action. Terdapat 154 kontraktor yang mampu memenuhi dokumen CSMS dan menjadi rekanan PT. X. Namun, pelaksanaan perencanaan (plan) yang meliputi identifikasi risiko, prakualifikasi, dan seleksi pada prosedur SMT-KKK-26 masih membutuhkan perbaikan karena belum sesuai dengan pelaksanaan pengadaan jasa di lapangan akibat adanya perubahan struktur organisasi di PT. X. Begitu pula dengan pelaksanaan $d o$, check, dan action yang dapat berjalan lebih optimal dengan adanya form evaluasi baku untuk menilai pekerjaan yang dilaksanakan oleh kontraktor.
\end{abstract}

Kata kunci: CSMS, siklus PDCA, prosedur, kontraktor 


\section{PENDAHULUAN}

PT. X bergerak dalam bidang industri agrokimia, khususnya untuk memenuhi kebutuhan pupuk domestik, baik untuk sektor tanaman pangan melalui distribusi pupuk bersubsidi maupun untuk sektor perkebunan. Saat ini PT. X memiliki kapasitas produksi urea 3,43 juta ton per tahun, amonia sebanyak 2,74 juta ton per tahun dan NPK 350 ribu ton per tahun. Tingginya kegiatan produksi yang dilakukan oleh PT. X menghadapkan pekerja pada berbagai risiko yang terdapat pada tempat kerja.

PT. X terus melakukan pengembangan, perbaikan dan modifikasi terhadap pabrik dan sarana pendukungnya dengan menunjuk perusahaan kontraktor/subkontraktor sebagai pelaksana pekerjaan. Intensitas proyek dan paket pekerjaan yang tinggi tersebut menyebabkan banyaknya kontraktor dan subkontraktor bekerja di dalam area PT. X, sehingga dibutuhkan pengendalian dan pengawasan yang ketat untuk memastikan kontraktor yang bekerja di kawasan PT. X adalah kontraktor yang peduli terhadap Keselamatan dan Kesehatan Kerja. Sehingga dapat mencegah terjadinya kecelakaan kerja. CSMS (Contractor Safety Management System) merupakan salah satu bagian dari Sistem Manajemen Keselamatan dan Kesehatan Kerja yang diterapkan dengan tujuan untuk memastikan bahwa proyek yang dikerjakan oleh kontraktor menerapkan norma-norma keselamatan dan kesehatan kerja.

CSMS digunakan oleh user dalam menilai kinerja kontraktor yang akan menjadi rekanan dalam pelaksanaan pekerjaannya. Hal ini dapat menjadi salah satu upaya pencegahan dalam pengendalian kecelakaan kerja yang terjadi pada kontraktor. Disebutkan dalam Tarwaka (2012) bahwa kecelakaan kerja merupakan kejadian yang jelas tidak dikehendaki dan tidak terduga yang dapat menimbulkan kerugian baik dari segi waktu, harta benda atau properti, maupun korban jiwa.

Kecelakaan (accident) berdasarkan teori Frank E. Bird Petersen merupakan suatu kejadian yang tidak dikehendaki, dapat mengakibatkan kerugian jiwa serta kerusakan harta benda dan biasanya terjadi akibat dari adanya sumber energi yang melebihi ambang batas atau struktur (Ramli, 2010).

Menurut Ramli (2010), Contractor Safety Management System (CSMS) dilaksanakan dalam tahap administratif dan tahap implementasi. Tahap administrasi terdiri dari Risk Assessment, PraKualifikasi, dan Seleksi. Tahap implementasi terdiri dari awal pekerjaan, pelaksanaan pekerjaan, dan evaluasi akhir pekerjaan.

CSMS dilaksanakan sebagai salah satu pemenuhan Peraturan Pemerintah RI No. 50 Tahun 2012 mengenai Sistem Manajemen Keselamatan dan Kesehatan Kerja (SMK3) pasal 6 elemen C mengenai Pelaksanaan Rencana K3 disebutkan bahwa kegiatan dalam pelaksanaan rencana K3 paling sedikit meliputi Tindakan Pengendalian, Perancangan \& Rekayasa, Prosedur dan Instruksi Kerja, Penyerahan sebagian pelaksanaan Pekerjaan, Pembelian/Pengadaan barang dan Jasa.

Salah satu unsur dalam sistem manajemen $\mathrm{K} 3$ adalah proses manajemen yang digunakan untuk mengelola sistem manajemen yang biasa dikenal dengan siklus Plan-Do-Check-Action yang merupakan proses perencanaan, penerapan, pengukuran, dan pemantauan, serta tindak lanjut menuju peningkatan berkelanjutan (Ramli, 2010).

Selain itu, dijelaskan dalam Peraturan Menteri Pekerjaan Umum Nomor 9 Tahun 2008, SMK3 Konstruksi Pekerjaan Umum adalah SMK3 pada sektor jasa konstruksi yang berhubungan dengan kepentingan umum (masyarakat) antara lain pekerjaan konstruksi: jalan, jembatan, bangunan gedung fasilitas umum, sistem penyediaan air minum dan perpipaannya, drainase, pengolahan sampah, pengaman pantai, irigasi, bendungan, bendung, waduk, dan lainnya.

OSHA 29 CFR 1910.119 yang mengatur mengenai Process Safety Management of Highly Hazardous Chemicals juga menyebutkan pada elemen keenam mengenai Contractor Obligation. Di dalamnya disebutkan kewajiban kontraktor sebelum menjadi rekanan perusahaan, termasuk mengenai pemenuhan dokumen-dokumen terkait rencana pelaksanaan pekerjaan.

Sebagai bentuk pencegahan dan control dari manajemen, PT. X membentuk peraturan mengenai penerapan aspek Keselamatan dan Kesehatan Kerja (K3) dan Lingkungan Hidup (LH) dalam SMTKKK-26 (Surat Manajemen Terpadu-Keselamatan dan Kesehatan Kerja -26). Dalam peraturan tersebut dijelaskan mengenai proses pengadaan jasa yang melibatkan kontraktor maupun subkontraktor harus menerapkan tahapan-tahapan yang ada dalam CSMS. Proses pengadaan jasa di PT. X melibatkan banyak departemen di dalamnya sebagai pelaksana, diantaranya Departemen Pengadaan Jasa, Departemen Perencanaan dan Pengendalian, Departemen K3, Departemen LH dan user yang membutuhkan pekerjaan itu sendiri. 


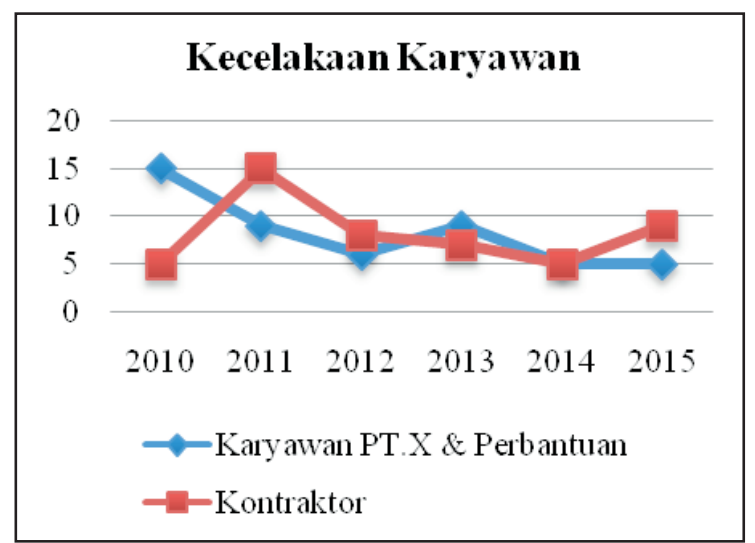

Sumber: Data Kecelakaan Kerja PT. X, Tahun 2015

Gambar 1. Data Kecelakaan Kerja PT. X

Pengaturan SMT-KKK-26 seharusnya mengendalikan pelaksanaan pekerjaan yang dilakukan oleh kontraktor. Akan tetapi, berdasarkan data kecelakaan kerja yang tercatat di PT. X, terlihat bahwa tren kecelakaan kerja lebih banyak terjadi pada pekerja kontraktor dibanding dengan karyawan PT. X itu sendiri. Berikut merupakan data kecelakaan kerja PT. X tahun 2015:

Pelaksanaan pekerjaan yang dilimpahkan pada kontraktor maupun subkontraktor meliputi pekerjaan dengan waktu pengerjaan berjangka panjang dan jangka pendek. Contoh pekerjaan dengan waktu pengerjaan berjangka waktu panjang adalah pekerjaan bongkar muat. Sebagaimana diketahui PT. X merupakan perusahaan yang memiliki intensitas produksi tinggi dan terus melakukan kegiatan jual-beli baik melalui jalur darat maupun laut. Setelah ditelusuri, ternyata kecelakaan kerja yang terjadi pada kontraktor lebih banyak dialami oleh Tenaga Kerja Bongkar Muat (TKBM).

Berdasarkan data kecelakaan kerja PT. X terlihat angka kecelakaan kerja dari kontraktor yang cukup signifikan. Walaupun kecelakaan kerja lebih banyak terjadi pada tenaga kerja bongkar muat, tetapi masih tercatat kecelakaan yang terjadi pada pekerjaan kontraktor. Dibutuhkan pengendalian dan pengawasan yang ketat untuk memastikan kontraktor yang bekerja di kawasan PT. X adalah kontraktor yang peduli terhadap keselamatan dan kesehatan kerja.

Oleh karena itu, penelitian ini bertujuan untuk melakukan analisis terhadap pelaksanaan Contractor Safety Management System yang telah dituangkan dalam SMT-KKK-26 PT. X dengan menggunakan siklus PDCA (Plan, Do, Check, Action).

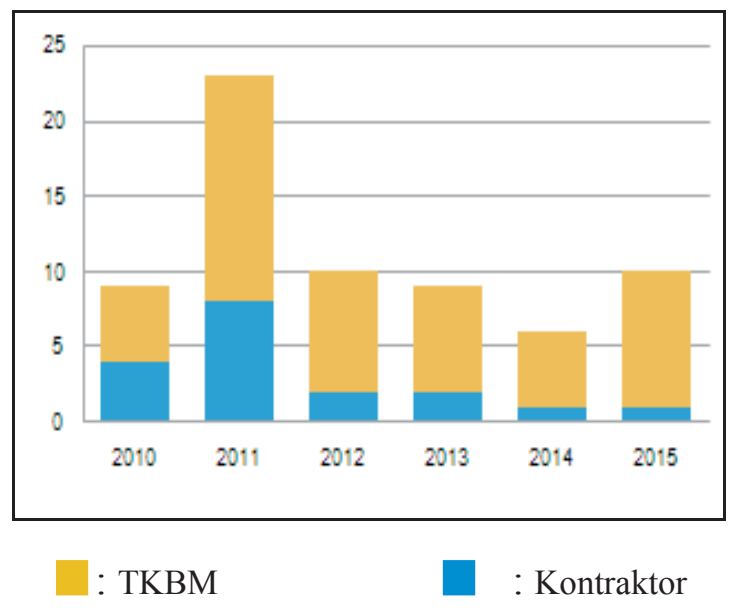

Sumber: Data Kecelakaan Kerja PT. X Tahun 2015

Gambar 2. Data Kecelakaan Kerja Kontraktor PT. X

Siklus PDCA memberikan kerangka kerja untuk melakukan perbaikan suatu proses atau suatu sistem. Implementasi dari siklus PDCA dapat digunakan untuk pengembangan produk baru berdasarkan kebutuhan kualitas pelanggan (Charantimath, 2011).

Permasalahan mengenai kecelakaan kerja yang terjadi pada karyawan kontraktor diharapkan dapat diminimalisir dengan penerapan program CSMS yang terus menerus mengalami perbaikan.

\section{METODE}

Penelitian ini dilaksanakan dengan menggunakan metode observasional dengan analisa data deskriptif karena data yang diperoleh didapatkan melalui pengamatan langsung terhadap objek penelitian tanpa memberikan intervensi atau perlakuan apapun. Penelitian menekankan pada pengumpulan fakta dan identifikasi data. Ditinjau dari segi waktu, penelitian ini bersifat cross sectional karena dilakukan serentak dalam satu waktu tertentu.

Penelitian dilaksanakan di PT. X, Bontang, Kalimantan Timur. Waktu penelitian dilaksanakan pada Februari hingga Maret 2017. Data yang terdiri dari data primer dan sekunder didapatkan dengan melakukan wawancara dan observasi yang diberikan pada beberapa departemen yang terlibat dalam proses pengadaan jasa, seperti Departemen Pengadaan Jasa, Departemen Perencanaan dan Pengendalian, Departemen K3, Departemen Penerimaan dan Pergudangan, Departemen LH, dan Departemen Perencanaan Pengadaan Barang dan Jasa. 
Penelitian ini dilakukan dengan menampilkan hasil yang bersifat uraian dari hasil wawancara dan studi dokumentasi. Kemudian data yang telah diperoleh akan dianalisis dalam bentuk narasi deskriptif menggunakan pendekatan siklus PDCA Deming.

\section{HASIL}

Penerapan Contractor Safety Management System (CSMS) di PT. X dituangkan dalam peraturan SMT-KKK-26 mengenai prosedur penerapan aspek K3 dan LH dalam proses pengadaan jasa. Sebagaimana dijelaskan bahwa proses pengadaan jasa PT. X melibatkan berbagai departemen dalam pelaksanaannya, sehingga dibutuhkan integrasi dari setiap departemen demi berjalannya proses pengadaan jasa sesuai dengan prosedur telah ditetapkan.

Prosedur SMT-KKK-26 memuat tahap demi tahap penerapan CSMS yang disesuaikan dengan struktur organisasi PT. X yang berhubungan dengan proses pengadaan jasa. Prosedur ini juga mencantumkan beberapa tahapan dalam CSMS yang dimulai dengan identifikasi risiko hingga evaluasi akhir pekerjaan. Setelah disahkan pada pertengahan tahun 2012, prosedur ini mengharuskan para kontraktor maupun subkontraktor yang akan menjadi rekanan PT. X untuk mengurus sertifikat CSMS. Kontraktor harus memenuhi persyaratan dokumen CSMS untuk mendapatkan sertifikat CSMS tersebut.

Berikut merupakan flowchart mengenai proses pengadaan jasa PT.X sesuai dengan prosedur SMTKKK-26:

Gambar 3A menjelaskan prosedur permintaan pengadaan jasa oleh unit kerja/user yang ditujukan kepada Departemen Pengadaan Jasa. Sebelum masuk ke Departemen Pengadaan Jasa, Pengajuan Permintaan Pengadaan (PPP) Jasa yang meliputi TOR dan owner estimate terlebih dahulu di-review oleh Departemen Perencanaan dan Pengendalian yang menghasilkan service request (SR) serta Departemen PPBJ yang menghasilkan Purchase Requistion (PR). Departemen Keselamatan dan Kesehatan Kerja melakukan identifikasi dan penilaian risiko pekerjaan untuk menentukan tingkat risiko dari pekerjaan yang akan dilaksanakan.

Departemen Pengadaan Jasa akan mengundang kontraktor yang sesuai dengan Daftar Usulan Rekanan (DUR) untuk mengikuti aanwijzing sebagaimana terlihat pada gambar 3B. Pada

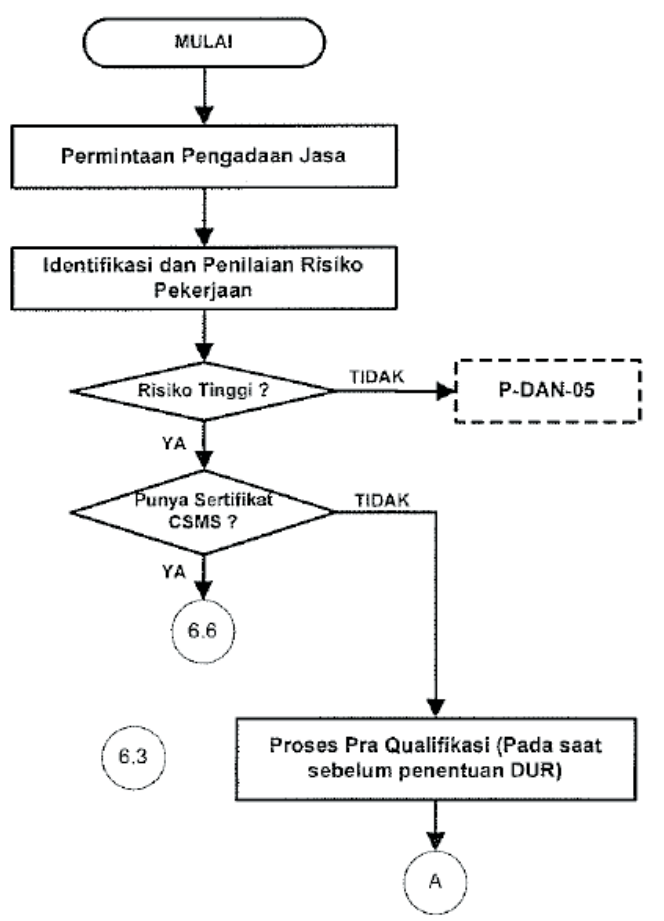

Gambar 3A. Prosedur Penerapan Aspek K3 dan LH pada Pengadaan Jasa PT. X

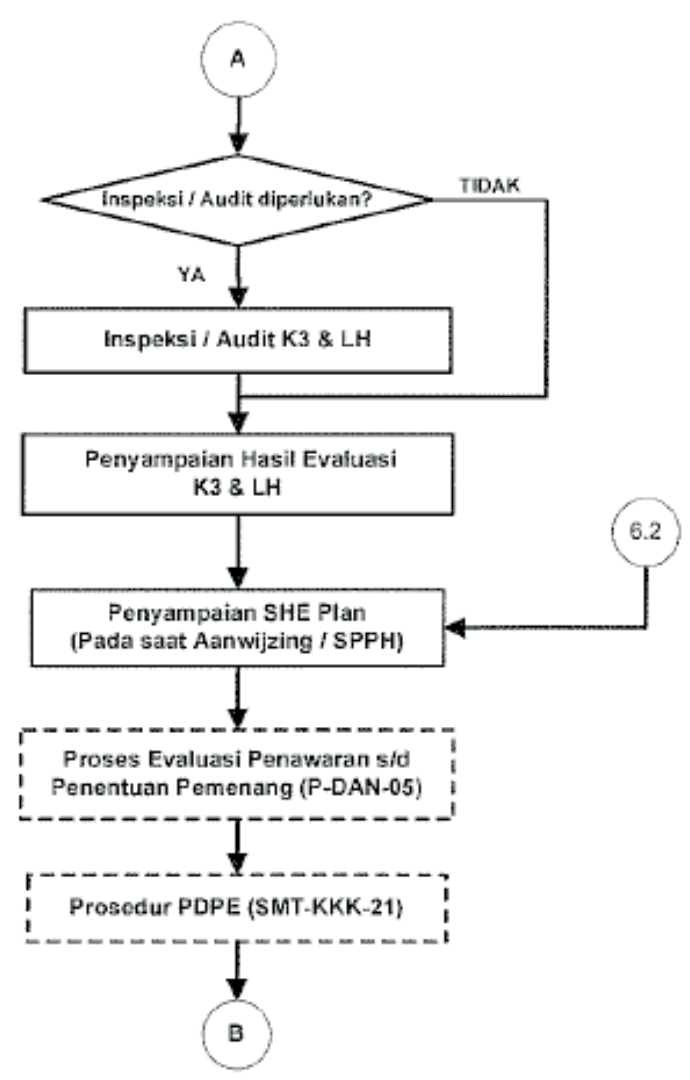

Gambar 3B. Prosedur Penerapan Aspek K3 dan LH pada Pengadaan Jasa PT. X (Lanjutan) 


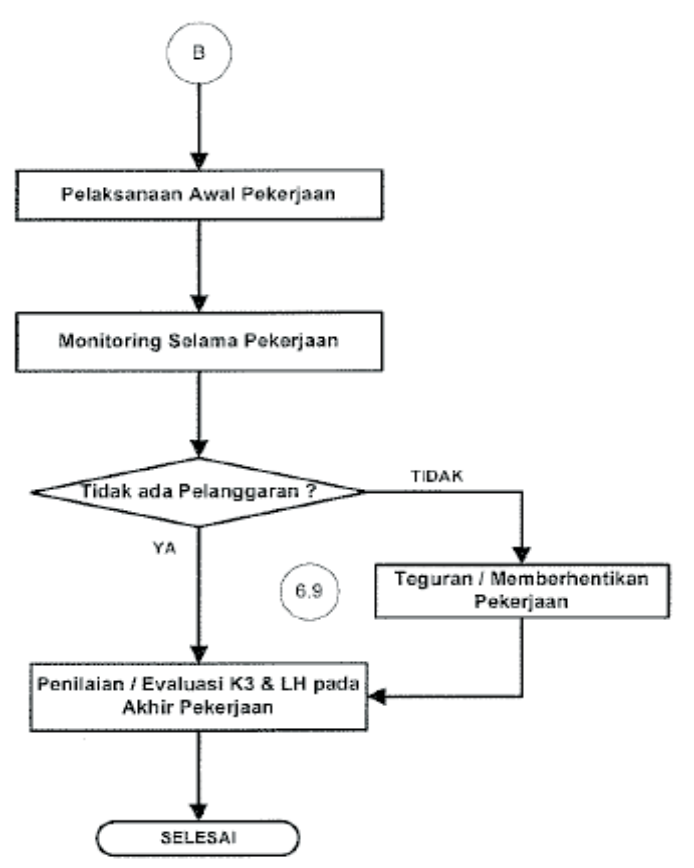

Gambar 3C. Prosedur Penerapan Aspek K3 dan LH pada Pengadaan Jasa PT. X (Lanjutan)

pelaksanaan aanwijzing akan dibahas mengenai penawaran yang diberikan kepada PT. X. Hal ini mencakup harga penawaran, scope of work, dan SHE Plan.

Gambar 3C menunjukkan awal pelaksanaan pekerjaan dan monitoring yang terus dilaksanakan selama pelaksanaan pekerjaan untuk melihat kesesuaian rencana dengan kenyataan di lapangan. Apabila ditemukan pelanggaran atau kelalaian pihak vendor yang melanggar kontrak, maka akan diberikan teguran atau bahkan pemberhentian pekerjaan yang dirasa sangat membahayakan. Tahapan CSMS berlanjut sampai pekerjaan selesai, yaitu dilaksanakannya evaluasi terhadap hasil pekerjaan terutama menyangkut aspek K3LH.

Berdasarkan hasil observasi yang dilakukan, terdapat ketidaksesuaian alur pengadaan jasa antara prosedur yang tertulis pada prosedur dengan pelaksanaan di lapangan. Selain itu, terdapat beberapa responden yang berasal dari departemen yang terlibat dalam proses pengadaan jasa belum memahami prosedur SMT-KKK-26.

Berikut merupakan flowchart hasil observasi proses pengadaan jasa di PT. X yang sedang berjalan:

Sebagaimana digambarkan dalam gambar 4, proses pengadaan jasa di PT. X dimulai dengan permintaan pengadaan jasa yang diajukan oleh

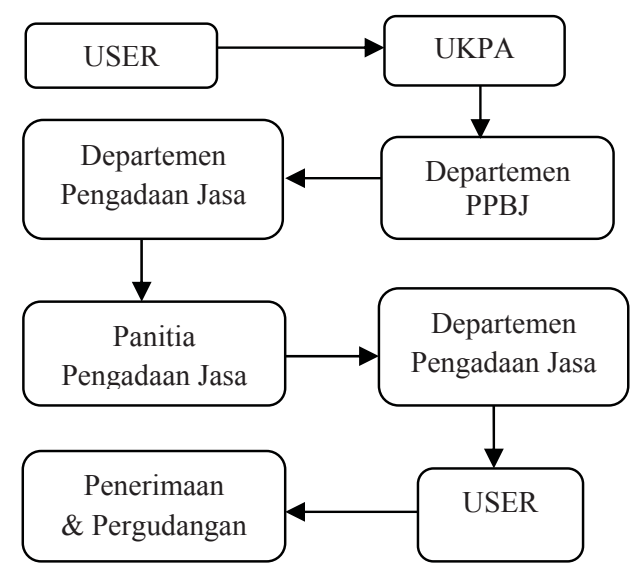

Gambar 4. Proses Pengadaan Jasa PT. X

user. User terlebih dahulu menyusun TOR untuk pelaksanaan pekerjaan dan juga usulan anggaran biaya. Kedua hal tersebut akan di-review oleh Unit Kerja Pengelola Anggaran (UKPA) yang berhubungan dengan user. UKPA dapat berasal dari berbagai departemen sesuai dengan kebutuhan pelaksanaan pekerjaan yang akan dilakukan, misalnya Departemen Perencanaan dan Pengendalian TA. UKPA akan menyusun SR (Service Request) setelah melakukan review terhadap TOR dan usulan owner estimate yang telah dibuat oleh user. Service request akan dikirimkan pada Departemen PPBJ (Perencanaan Pengadaan Barang dan Jasa) untuk di-review kembali, serta memastikan ketersediaan anggaran berdasarkan yang tertulis dalam SR yang dikirim oleh UKPA tersebut. Apabila sudah dapat dipastikan anggaran tersedia maka Departemen PPBJ akan menerbitkan PR (Purchase Requisition) dan siap diserahkan pada Departemen Pengadaan Jasa dalam menunjuk penyedia jasa yang akan melakukan pekerjaan. Dalam pelaksanaan pengadaan penyedia jasa ini dibentuklah panitia pengadaan jasa dalam proses kualifikasi kontraktor. Setelah proses kualifikasi selesai maka akan ditindaklanjuti dengan kontrak pekerjaan oleh Departemen Pengadaan Jasa.

Setelah pekerjaan selesai, akan dilakukan evaluasi oleh user untuk selanjutnya ditindaklanjuti oleh Departemen Penerimaan dan Pergudangan. Departemen Penerimaan dan Pergudangan akan menerbitkan Berita Acara Pemeriksaan Pekerjaan yang di dalamnya terdapat nilai VPR (Vendor Performance Rating).

Pelaksanaan CSMS di PT. X sesuai dengan Prosedur SMT-KKK-26: 


\section{Identifikasi Risiko}

Dalam SMT-KKK-26 sudah dicantumkan form identifikasi risiko yang digunakan dalam menilai pekerjaan yang akan dilakukan di PT. X. Adapun beberapa daerah risiko yang termasuk ke dalam penilaian risiko PT. X meliputi jenis pekerjaan, lokasi kerja, material/peralatan yang digunakan, potensi paparan terhadap bahaya di tempat kerja, potensi paparan terhadap bahaya bagi semua personil, pekerjaan secara bersamaan oleh kontraktor yang berbeda, jangka waktu pekerjaan, konsekuensi insiden yang potensial, pengalaman kontraktor, serta paparan terhadap publisitas negatif.

Sebagaimana dijelaskan dalam SMT-KKK-26, identifikasi risiko dilakukan oleh Departemen K3. Akan tetapi, sampai saat ini pelaksanaan identifikasi risiko ini belum efektif berjalan karena belum adanya komunikasi yang strategis antara Departemen Pengadaan Jasa dan Departemen K3. Dalam pengaturan tanggung jawab dan prosedur SMTKKK-26 poin 6.1.2.1 departemen K3 seharusnya melaksanakan penilaian risiko pekerjaan berdasarkan copy dokumen Permintaan Pelaksanaan Pekerjaan (PPP) dan rincian pekerjaan dari Departemen Pengadaan Jasa ketika akan dilaksanakan suatu pekerjaan. Dikarenakan prosedur ini belum berjalan dengan baik dan tidak ada pemberitahuan secara sistematis dari Departemen Pengadaan Jasa, maka sejauh ini identifikasi risiko pekerjaan belum dijalankan.

\section{Pra-Kualifikasi}

Berdasarkan hasil observasi yang telah dilakukan oleh peneliti, Divisi JPP dan Departemen Pengadaan Jasa telah mencantumkan keharusan rekanan memiliki sertifikat CSMS yang dijelaskan pada dokumen Aanwijzing.

Tahap pra-qualifikasi merupakan tahap awal seleksi dalam pemenuhan persyaratan guna mendapatkan sertifikat CSMS. Selama ini penilaian dokumen CSMS dilaksanakan oleh tim yang ada dalam Departemen K3. Berdasarkan SMT-KKK-26 poin 5.11, dijelaskan bahwa Departemen K3 dan LH melakukan penilaian terhadap questionnaire CSMS dalam waktu maksimal 3 hari. Akan tetapi, hal ini masih belum berjalan secara maksimal karena faktanya penilaian dokumen CSMS seringkali melewati batas waktu tersebut, karena SDM yang mampu melakukan penilaian terhadap dokumen CSMS masih sedikit.

Hingga bulan Maret 2017 terdapat 154 kontraktor yang menjadi rekanan PT. X. Berdasarkan keterangan responden yang merupakan tim CSMS Departemen K3, setiap minggu selalu ada kontraktor yang mengajukan dokumen CSMS demi mendapatkan sertifikat CSMS PT. X, namun tidak semua kontraktor tersebut memenuhi persyaratan administrasi minimal yang diberikan perusahaan.

\section{Seleksi}

Sebelum melakukan seleksi kontraktor, PT.X terlebih dahulu melaksanakan Aanwijzing. Aanwijzing dilaksanakan untuk menyampaikan penilaian risiko atas pekerjaan yang akan dilaksanakan dan menyampaikan hal-hal yang harus dipenuhi oleh kontraktor. Selanjutnya kontraktor akan membuat perencanaan pekerjaan yang disusun dalam SHE Plan. Dokumen tersebut juga menjadi salah satu pertimbangan pemilihan kontraktor saat kick of meeting.

Berdasarkan hasil interview dengan responden dari kontraktor yang telah menjadi rekanan PT. $\mathrm{X}$, proses seleksi yang dilaksanakan Departemen Pengadaan Jasa belum mengutamakan aspek K3 . Hal ini disampaikan karena ada kejadian dimana pemenang tender adalah kontraktor yang belum memiliki sertifikat CSMS.

\section{Awal Pekerjaan}

Sesuai dengan SMT-KKK-26 pada poin 6.7 Departemen K3 dan Departemen LH bertugas untuk memberikan pengarahan dalam penerapan aspek K3 dan LH pada pekerjaan yang akan berlangsung. Departemen LH menugaskan petugas pemantau lingkungan untuk memonitor kondisi lingkungan dan mengarahkan kontraktor untuk melakukan pengelolaan lingkungan. Tahap awal pekerjaan dilakukan oleh pihak kontraktor dalam pemenuhan beberapa aspek K3, yaitu work permit, pembuatan JSA, dan penyampaian SHE Plan.

Berdasarkan hasil kuesioner pada tujuh kontraktor yang sedang menjalankan proyek di PT. X, mereka telah membuat dan menyelesaikan work permit serta JSA. Akan tetapi, berdasarkan hasil wawancara, responden dari departemen K3 menyatakan bahwa pemenuhan SHE Plan masih sering terlewatkan dari pengawasan. 
Pemenuhan Laporan Bulanan Kontraktor

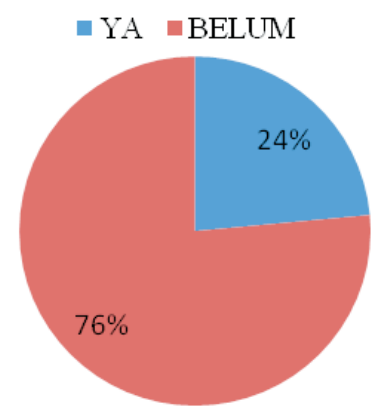

Gambar 5. Gambaran Pemenuhan Laporan Bulanan oleh Kontraktor di PT. X

\section{Pelaksanaan Pekerjaan}

Selama pekerjaan berlangsung, Departemen K3 bertugas melaksanakan monitoring atas pekerjaan tersebut. Hal ini sudah berjalan dengan baik karena Departemen K3 selalu melakukan inspeksi pada setiap harinya. Selain itu, kontraktor juga wajib mengirimkan laporan bulanan pada Departemen K3. Akan tetapi, berdasarkan rekapitulasi pemenuhan laporan bulanan oleh kontraktor yang dimiliki Departemen K3, didapatkan hasil sebagai berikut:

Berdasarkan data pemenuhan laporan bulanan yang dimiliki departemen $\mathrm{K} 3$, sebanyak $76 \%$ kontraktor belum secara rutin menyerahkan laporan bulanan atas pekerjaannya tersebut.

\section{Evaluasi Akhir Pekerjaan}

Pada tahap akhir, Departemen K3 seharusnya melaksanakan evaluasi penerapan norma-norma K3 terhadap pekerjaan kontraktor secara keseluruhan. Sebagaimana dijelaskan dalam SMT-KKK-26 poin 6.10, evaluasi tersebut nantinya akan menjadi bahan evaluasi Departemen Pengadaan Jasa dalam penyusunan Vendor Performance Rating. Akan tetapi, berdasarkan hasil interview dengan responden dari Departemen Pengadaan Jasa, evaluasi yang selama ini sudah berjalan adalah evaluasi oleh user atas penyelesaian pekerjaan yang dilakukan.

\section{PEMBAHASAN}

Pelaksanaan CSMS dalam proses pengadaan jasa PT. X mengacu pada prosedur SMT-KKK-26, akan tetapi pelaksanaan prosedur tersebut belum sesuai dengan pelaksanaan di lapangan.
Menurut Charantimath (2011), plan yang berada pada siklus PDCA dimulai dengan menemukan penyebab masalah yang terdeteksi pada desain dan pengembangan produk.

Berdasarkan hasil observasi yang dilakukan, hal yang menyebabkan ketidaksesuaian prosedur yang tertulis dengan pelaksanaan di lapangan adalah perubahan struktur organisasi PT. X yang mengakibatkan bertambahnya departemen yang terlibat dalam proses pengadaan jasa.

Berdasarkan analisis mengenai pelaksanaan CSMS yang termasuk dalam perencanaan (plan) pada siklus PDCA dimulai dengan identifikasi risiko, proses pra kualifikasi, dan seleksi. Ketiga hal tersebut berada pada tahap administrasi dalam flowchart Gambar 6.

Kemudian pada pelaksanaan (do) terdapat pre-job activity dan job in progress. Sedangkan evaluasi merupakan wujud penerapan check dalam siklus PDCA. Action dilakukan dengan memulai kembali tahapan CSMS dari awal dengan perbaikan berkelanjutan.

Berikut merupakan analisis tahapan yang ada pada prosedur SMT-KKK-26 mengenai penerapan aspek K3 dan LH pada pengadaan jasa yang diterapkan di PT. X yang termasuk dalam aspek perencanaan:

\section{Identifikasi Risiko}

Tahap pertama dalam aplikasi PDCA yaitu plan. Melaksanakan perencanaan diperlukan suatu analisa untuk memperbaiki dan mencari area yang memiliki peluang untuk diubah (Kreitner, 2009).

Identifikasi risiko merupakan salah satu metode yang digunakan untuk mencari permasalahan di lapangan terhadap hal-hal berisiko selama pekerjaan

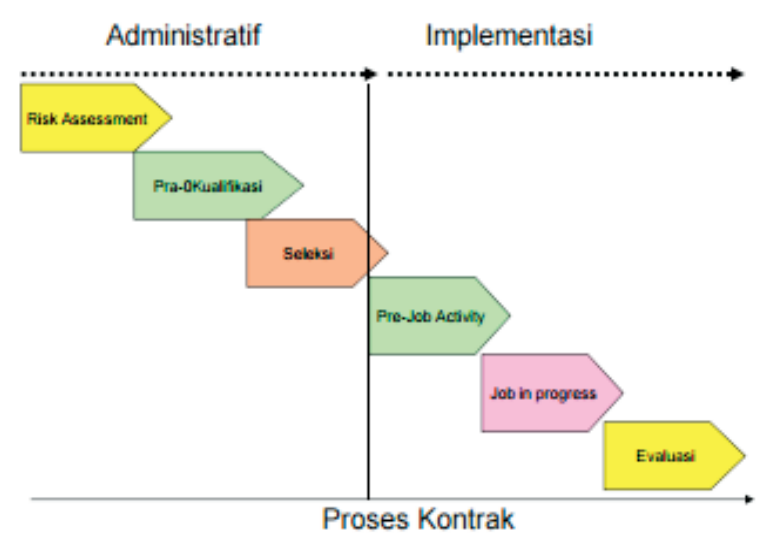

Gambar 6. Tahapan CSMS 
berlangsung. Dengan mengetahui berbagai kemungkinan permasalahan yang dapat terjadi di lapangan memudahkan proses perencanaan yang dirumuskan.

Tahapan identifikasi risiko bertujuan untuk mengidentifikasi semua kemungkinan bahaya atau risiko yang mungkin terjadi di lingkungan kegiatan dan bagaimana dampak atau keparahannya jika terjadi (Ramli, 2010).

Menurut Ramli 2010, pekerjaan kontraktor diklasifikasikan berdasar tingkat risiko atau bahaya. Pekerjaan diklasifikasikan menjadi pekerjaan dengan risiko tinggi, risiko sedang, dan risiko rendah.

Pada PT. X terdapat 10 aspek yang telah disebutkan pada hasil penelitian yang termasuk ke dalam penilaian risiko terhadap pekerjaan yang akan dilakukan. Penilaian terhadap 10 aspek tersebut dilakukan dengan mengidentifikasi ke dalam tiga golongan konsekuensi yaitu Rendah, Sedang, dan Tinggi.

Apabila dianalisa kembali, pengaturan prosedur mengenai identifikasi risiko dalam SMT-KKK26 cukup membutuhkan proses yang lama dan cenderung tidak efisien. Hingga saat ini, identifikasi risiko belum dijalankan secara optimal sesuai dengan flowchart prosedur yang ada. Departemen Pengadaan Jasa belum memberikan copy PPP sebagai pemberitahuan untuk dilaksanakannya identifikasi risiko karena pemahaman SDM yang belum cukup baik terhadap SMT-KKK-26. Selain itu, pekerjaan Departemen Pengadaan Jasa cenderung memiliki tuntutan deadline yang padat. Sejauh ini diasumsikan bahwa tingkatan risiko atas pekerjaan yang berada dalam pabrik tergolong tinggi sehingga seharusnya mengikuti aturan prosedur SMT-KKK-26 sebagaimana dijelaskan dalam poin 6.2.1.5.

Berdasarkan analisa diatas, ditemukan area yang memiliki peluang untuk diadakannya suatu perbaikan, yaitu perubahan alur pelaksanaan pengadaan jasa di PT. X, sehingga dapat disusun plan sesuai dengan keadaan organisasi. Salah satunya dengan mengarahkan user untuk terlebih dahulu melaksanakan identifikasi risiko sebelum proses pengadaan jasa.

Berdasarkan pembahasan diatas, terlihat bahwa perencanaan yang dilakukan terkait pelaksanaan identifikasi risiko masih belum berjalan secara optimal. Identifikasi risiko menjadi perencanaan pertama yang dilakukan dalam tahapan CSMS, sehingga diperlukan perbaikan perencanaan pelaksanaan identifikasi risiko agar memperlancar pelaksanaan pada tahap selanjutnya.

\section{Pra-Kualifikasi}

Apabila ada pekerjaan yang harus dilakukan, tidak masuk akal untuk menjalankan pekerjaan tersebut dengan terburu-buru tanpa memikirkan terlebih dahulu cara melaksanakannya. Diperlukan perencanaan untuk menentukan siapa yang akan melakukannya, berapa lama waktu yang dibutuhkan, apa sebenarnya yang akan dilakukan, informasi dan material dari luar akan dibutuhkan dan perkembangan dapat dipantau (Wealleans, 2001).

Proses prakualifikasi yang berada pada tahap administrasi ini termasuk dalam suatu perencanaan yang dilakukan oleh manajemen perusahaan. Tahapan ini dilaksanakan untuk merumuskan perencanaan pekerjaan yang akan dilakukan dengan menyaring kontraktor terbaik yang dapat memenuhi persyaratan.

Pada tahap prakualifikasi, perusahaan juga memberikan ketentuan yang terdapat dalam dokumen aanwijzing. Dokumen tersebut memberikan penjelasan scope pekerjaan yang akan dilakukan serta ketentuan kontraktor yang dibutuhkan dalam pekerjaan tersebut. Persyaratan pemenuhan sertifikat CSMS juga berada pada dokumen aanwijzing. Hal ini menunjukkan bahwa proses menyaring kontraktor dalam penentuan pelaksana pekerjaan di PT.X cukup ketat karena untuk mendapatkan sertifikat CSMS itu sendiri kontraktor harus memenuhi persyaratan yang tidak mudah.

\section{Seleksi}

Pelaksanaan aanwijzing yang dilaksanakan oleh PT. X sesuai dengan Keputusan Presiden Republik Indonesia Nomor 18 Tahun 2000 tentang Pedoman Pelaksanaan Pengadaan Barang/Jasa instansi pemerintah. Di dalamnya dijelaskan bahwa tugas, wewenang, dan tanggung jawab panitia pengadaan barang/jasa ditetapkan untuk menyusun jadwal dan menetapkan cara pelaksanaan serta lokasi. Pada pelaksanaan aanwijzing disampaikan mengenai scope pekerjaan yang meliputi waktu pelaksanaan, lokasi pekerjaan, material yang dibutuhkan, dan beberapa persyaratan yang harus dipenuhi kontraktor lainnya.

Berdasarkan keterangan responden dari Departemen Pengadaan Jasa, lolosnya kontraktor yang belum memiliki sertifikat CSMS mungkin terjadi karena pertimbangan beberapa aspek lain, 
seperti: harga, manpower yang dimiliki kontraktor, pengalaman perusahaan, peralatan yang digunakan, dan lain-lain. Selain itu, pengadaan jasa akan tetap mempersyaratkan sertifikat CSMS bagi pemenang tender dan memberikan waktu pemenuhannya hingga pelaksanaan kick of meeting.

Bersamaan dengan pelaksanaan kick of meeting, kontraktor akan menjelaskan SHE Plan yang telah dirumuskan sebelumnya.

\section{Awal Pekerjaan}

Bila proses perencanaan sudah dirasa cukup, yang selanjutnya harus dilakukan adalah mulai mengambil tindakan. Objective dari tahap pelaksanaan ini nampaknya sudah cukup, akan tetapi kerangka tersebut belum terpenuhi tanpa adanya perencanaan (Weallens, 2001).

Pra pelaksanaan pekerjaan adalah komunikasi awal antara pihak kontraktor yang memenangkan tender (Santoso, et al., 2015).

Kurang sesuainya pemenuhan dokumen SHE Plan dari kontraktor yang akan melaksanakan pekerjaan dapat disebabkan karena kurangnya integrasi antar Departemen. Departemen K3 tidak mampu mengontrol siapa saja kontraktor yang akan melaksanakan pekerjaan di PT. X apabila tidak ada pemberitahuan dari Departemen Pengadaan Jasa. Maka dari itu, integrasi antar departemen sangat dibutuhkan dalam menerapkan CSMS di PT. X.

Pemenuhan untuk pembuatan Job Safety Analysis dan Work Permit sejauh ini terkontrol untuk kontraktor-kontraktor yang terdata dengan baik sebagai rekanan PT. X. Pemenuhan JSA dan work permit ini merupakan tahap awal implementasi dari perencanaan yang terdapat pada SHE Plan kontraktor.

Menurut keterangan responden dari kontraktor menyebutkan bahwa Departemen K3 sangat tegas dalam menyaring kontraktor yang akan masuk melaksanakan pekerjaan di PT. X.

\section{Pelaksanaan Pekerjaan}

Pada tahap pelaksanaan pekerjaan ini sebenarnya terdapat dua tahap yang sedang berproses dalam siklus PDCA, yaitu Do dan Check.

Kontraktor akan melaksanakan pekerjaannya sesuai dengan perencanaan yang telah disusun dengan berbagai pengendalian risiko berdasarkan hasil penilaian risiko pekerjaan yang telah dilakukan.
Check atau memeriksa adalah dimana hasil dari implementasi pekerjaan tersebut diamati dan dianalisis terhadap rencana yang telah disusun sebelumnya (Charantimath, 2011).

Departemen K3 selalu melakukan inspeksi harian sebagai upaya pengawasan terhadap pekerjaan kontraktor yang sedang berjalan. Pengawasan tersebut juga disesuaikan dengan perencanaan dokumen SHE Plan yang telah diserahkan kontraktor kepada Departemen K3. Hal ini merupakan salah satu wujud upaya check yang dilakukan dalam peningkatan pelaksanaan pekerjaan.

Pelaksanaan inspeksi oleh Departemen K3 belum terdokumentasi dengan baik, sehingga belum ada catatan yang dapat digunakan untuk melakukan review pekerjaan kontraktor. Maka dari itu, seharusnya dirumuskan suatu form inspeksi baku yang dapat digunakan dalam melakukan pemantauan pekerjaan kontraktor. Hal ini dilakukan untuk memonitor sejauh apa tindakan yang telah dilakukan sebagai wujud dari perencanaan yang telah dilakukan.

Berdasarkan data pemenuhan laporan bulanan yang dimiliki departemen K3, sebanyak $76 \%$ kontraktor belum secara rutin menyerahkan laporan bulanan atas pekerjaannya tersebut.

Ketidakteraturan pembuatan laporan bulanan yang dibuat oleh kontraktor belum sesuai dengan prosedur yang ada dapat disebabkan karena berbagai hal. Salah satunya kurangnya informasi yang diberikan pada kontraktor pada saat awal pekerjaan sebelum pelaksanaan kick of meeting. Penyebab lain yang dapat memicu keterlambatan pelaporan tersebut adalah kurangnya kesadaran kontraktor dalam pemenuhan laporan.

Pada tahap pelaksanaan pekerjaan inilah aspek do dan check dijalankan. Inspeksi terhadap pekerjaan kontraktor dilaksanakan dengan terus adanya perbaikan yang disesuaikan dengan perencanaan yang dilakukan sebelum pekerjaan dilakukan. Laporan bulanan adalah salah satu bentuk pemeriksaan yang dilakukan untuk memastikan pelaksanaan pekerjaan berjalan dengan baik.

\section{Evaluasi Akhir Pekerjaan}

Evaluasi akhir pekerjaan merupakan evaluasi yang dilakukan pada kinerja Health and Safety Environment (HSE) kontraktor selama pelaksanaan pekerjaan yang ditugaskan (Lukiatsinto dan Widajati, 2014).

Berdasarkan hasil interview dengan responden dari Departemen Pengadaan Jasa, evaluasi yang 
selama ini sudah berjalan adalah evaluasi oleh user atas penyelesaian pekerjaan yang dilakukan. Prosedur mengenai pendokumentasian Vendor Performance Rating (VPR) masih kurang jelas, bahkan Departemen Pengadaan Jasa tidak memiliki dokumen VPR. Padahal VPR seharusnya digunakan untuk pedoman Departemen Pengadaan Jasa dalam melakukan seleksi kontraktor. Menurut responden dari Departemen Pengadaan Jasa, pada kenyataannya yang mendokumentasikan VPR adalah Departemen Penerimaan dan Pergudangan serta user itu sendiri. Hal ini menunjukkan ketidaksesuaian penerapan SMT-KKK-26 mengenai pelaksanaan evaluasi terhadap kontraktor. Hal ini bisa disebabkan karena perubahan struktur organisasi yang ada di PT.X. Selain itu, PT. X belum memiliki form evaluasi akhir yang baku.

Menurut Charantimath (2011), action merupakan tahapan dimana siklus berjalan kembali dan dilakukan perbaikan secara berkelanjutan. Sebagaimana pengertian tersebut, maka dibutuhkan perbaikan secara berkelanjutan dalam pelaksanaan tahapan CSMS. Evaluasi akhir pekerjaan dilakukan dengan harapan dapat menemukan permasalahan atau kesenjangan yang belum dilaksanakan secara optimal, sehingga pelaksanaan pekerjaan selanjutnya dapat dilakukan dengan lebih baik.

\section{SIMPULAN}

Berdasarkan hasil pengamatan terhadap penerapan Contractor Safety Management System (CSMS) di PT. X dapat disimpulkan bahwa CSMS yang dilaksanakan pada PT. X masih memerlukan beberapa perbaikan agar sesuai dengan kaidah siklus PDCA, Plan-Do-Check-Action.

Dibutuhkan perbaikan perencanaan (plan) yang dilakukan pada tahap identifikasi risiko agar berjalan lebih optimal dengan cara menyesuaikan flowchart SMT-KKK-26 dengan alur pengadaan jasa yang berjalan di lapangan. Hal ini diperlukan karena terdapat perubahan struktur organisasi di PT.X. Pelaksanaan tahap prakualifikasi dan seleksi yang termasuk dalam perencanaan (plan) sudah berjalan dengan baik.

Dalam pemenuhan kaidah do dan check siklus PDCA, masih diperlukan perbaikan dalam pelaksanaan monitoring yang dilakukan terhadap pekerjaan kontraktor. Salah satunya dengan optimalisasi pelaporan bulanan kontraktor. Hal ini dilakukan agar implementasi pekerjaan sesuai dengan perencanaan yang dilakukan.
Evaluasi akhir pekerjaan yang dilakukan dalam peningkatan berkelanjutan sebagai wujud dari action dalam kaidah PDCA membutuhkan perbaikan dengan cara pembuatan form baku untuk pelaksanaan evaluasi. Dengan demikian, dapat ditemukan beberapa hal yang membutuhkan perbaikan dalam pelaksanaan CSMS untuk pekerjaan selanjutnya.

\section{DAFTAR PUSTAKA}

Charantimath, Poornima M. 2011. Total Quality Management Second Edition. Chandigarh: Pearson.

Keputusan Presiden Republik Indonesia Nomor 18 Tahun 2000 tentang Pedoman Pelaksanaan Pengadaan Barang/Jasa Instansi Pemerintah.

Kreitner, Robert. 2009. Management Eleventh Edition. Boston: Houghton Mifflin Hartcourt Publishing Company.

Lukiatsinto, R., Widajati, N. 2014. Penerapan CSMS (Contractor Safety Management System) sebagai Upaya Pencegahan Kecelakaan Kerja. The Indonesian Journal of Occupational Safety and Health, Vol. 3, No. 2. Tersedia di: http://journal.unair. ac.id/download-fullpapers-k3b7b4b53ea1full.pdf [diakses tanggal 19 April 2017].

Occupational Safety and Health Administration. 2000. Process Safety Management (OSHA 3132). U.S Department of Labor.

Peraturan Menteri Pekerjaan Umum Nomor 09 Tahun 2008 tentang Pedoman Sistem Manajemen Keselamatan dan Kesehatan Kerja (K3) Konstruksi Bidang Pekerjaan Umum.

Ramli, Soehatman. 2010. Sistem Manajemen Keselamatan \& Kesehatan Kerja OHSAS 18001. Jakarta: Dian Rakyat.

Ramli, Soehatman. 2010. Pedoman Praktis Manajemen Risiko dalam Perspektif K3 OHS Risk Management. Jakarta: Dian Rakyat.

Santoso, K.D., Wahyudi, I., Kurniawan, B. 2015. Analisis Implementasi Contractor Safety Management System (CSMS) terhadap Pekerjaan Berisiko Tinggi di PT Pertamina (Persero) Refinery Unit IV Cilacap. Jurnal Kesehatan Masyarakat, Volume 3, Nomor 3. (e-Journal). Tersedia di: <ejournal-s1.undip.ac.id/ index.php/jkm/article/download/12415/12047> [diakses tanggal 20 April 2017].

Tarwaka. 2012. Dasar-Dasar Keselamatan Kerja serta Pencegahan Kecelakaan Kerja di Tempat Kerja. Surakarta: Harapan Press.

Wealleans, David. 2001. The Organizational Measurement Manual. England: Gower. 